\title{
Egyptianizing the Classical Approaches of Post-disaster Housing
}

\author{
Adham Hany Abulnour \\ Department of Architecture and Environmental Design, Faculty of Engineering, Arab Academy for Science, Technology and \\ Maritime Transport-AAST, Abo Kir Campus, Alexandria 1029, Egypt
}

\begin{abstract}
This research is intended as a practical guide on how to custom-tailor post-disaster housing approaches to suit the countries in which they are implemented. Three classical approaches are chosen, discussed and analytically compared in order to unveil the shortcomings of their implementation in a country such as Egypt which is faced by technological, economic and time-related challenges in our current time. Strategies are synthesized to in order to overcome these challenges and enhance the prospect of implementing the approaches in the country. Finally, the research presents a series of recommendations which can guide the implementation of the strategically enhanced approaches while bearing reference to real-life challenges and opportunities.
\end{abstract}

Key words: Post-disaster housing, classical approaches, strategies, expediting implementation, integrating with governmental plans.

\section{Introduction and Statement of Problem}

In the aftermath of a disaster, local and state governments, in addition to charitable organizations, embark on several tasks to aid disaster-affected communities [1]. Different processes of sheltering and housing provision are employed through cycles of aid which extend from the "emergency response phase" (immediately after the strike of a disaster) to the stage of "post-disaster recovery" [2]. These processes include the provision of tents and imported/prefabricated design units. Also included is providing temporary housing and hazard-resistant structures [3].

In real-life, processes of post-disaster housing are implemented through a number of approaches. Among the classical (most used) approaches are: "Sheltering during Reconstruction-SDR”, "Three-Stage Recovery-3SR” and “Two-Stage Recovery-2SR” [4]. Each of these approaches has its requirements and expected outcomes which render its implementation in

Corresponding author: Adham Hany Abulnour, associate professor, research field: conservation and development of the urban context.
Egypt a subject worthy of investigation especially in light of the difficulties which affront the country in our current times.

\subsection{Research Aim, Objectives and Methodology}

The main aim of this research is to custom-tailor classical approaches of post-disaster housing in order to be suited for implementation in Egypt. To this end, the first objective of the research is to investigate the modus operandi of these approaches. The ensuing objective is to understand the factors which influence the approaches' suitability for implementation in the country. The ultimate objective of the research is to synthesize strategies which can "Egyptianize" the approaches while enhancing the prospect of their successful implementation.

In order to fulfill its aim and objectives, the research subjects the three classical approaches (SDR, 3SR and 2SR) to a comparative analysis which bears reference to Egypt's current conditions. Consecutively, the research builds upon the results of the comparative analysis to inductively synthesize a number of strategies which address the real-life implementation of these approaches. 
2. Discussion of Procedure: Comparing Classical Approaches of Post-disaster Housing

The SDR approach (Fig. 1: left) stipulates that a disaster-affected community is moved into tents/host families as a primary "emergency response" after the strike of a disaster. The community is then offered temporary structures which have the ability to develop into permanent and more hazard-resistant structures. With the passage of time, the community is expected (and ideally: encouraged) to carry on improvements and modifications to the structures until reaching their final (permanent) state.

In similarity to the SDR approach, the 3SR approach (Fig. 1: middle) starts by moving the affected communities after the onset of a disaster into tents/ host families. However, the community is not provided in the 3SR approach with temporary structures which have the ability to develop into a permanent house. Instead, the community relocates in a transitional shelter where people stay for a period of time until the construction of their prospected permanent houses is finished.

On another front the 2SR approach (Fig. 1: right) strives to eliminate transitional phases of housing provision in order for people to be directly moved from emergency shelters to permanent houses. This usually means designing and fostering emergency shelters with the ability of hosting disaster-affected communities for long periods of time. This approach also calls for promoting and expediting the construction of permanent houses [5].

In order to ensure subjectivity, this research comparatively analyzes the SDR, 3SR and 2SR approaches while bearing reference to a number of criteria which represent serious challenges to Egypt in our current times. These criteria are: lack of technological advances, inability to sustain high costs, urban sprawl, time consumption and the difficulty of promoting advanced logistics. Results of the comparative analysis are summarized in Table1.

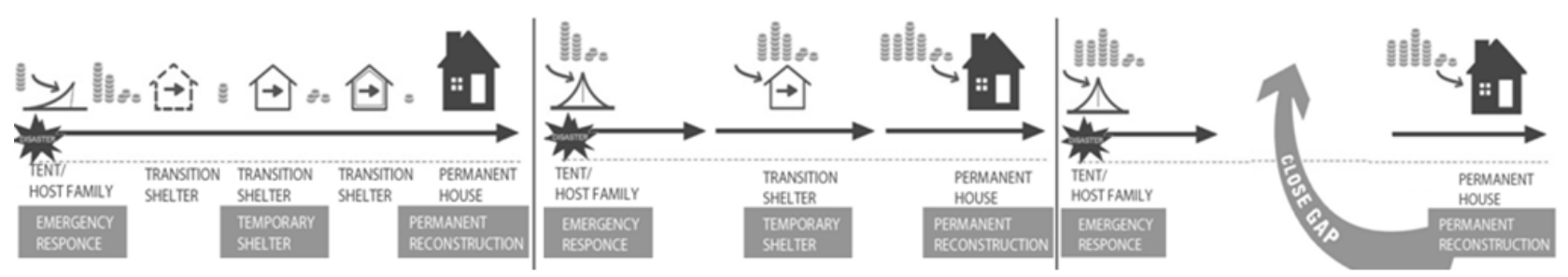

Fig. 1 Left: “Sheltering during reconstruction-SDR” approach. Middle: “Three stage recovery-3SR” approach. Right: “Two stage recovery-2SR” approach [4].

Table 1 Results of the comparative analysis.

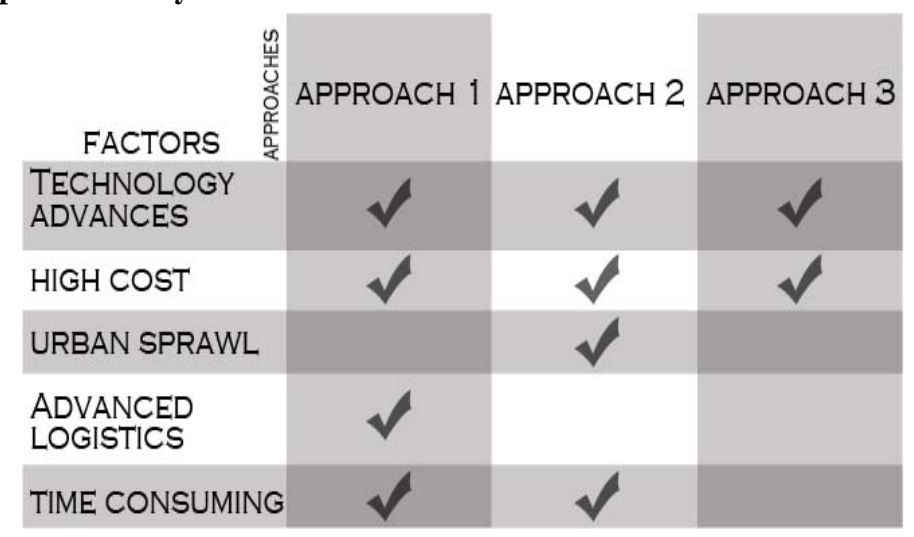


Post-disaster housing approaches, which stipulate transitional phases, have been frequently criticized due to a number of problems [3]. A major problem for the SDR and 3SR approaches is the apparent distinction, in industrialized countries, between temporary and permanent housing which cannot be readily applied to developing countries where a permanent house may be cheaper and built in less time than an imported sheltering or housing unit. The term "temporary" has frequently been used where a shelter or house has been designed for a short life-span, but owing to its cost of replacement, it inevitably becomes permanent [6]. Temporary shelters and houses have a tendency to remain for much longer than anticipated because the flow of international aid to build permanent housing diminishes over time. Accordingly, if there are no long-term plans for permanency, temporary shelters and houses will become permanent ones. The unplanned evolution of temporary shelters and houses into permanent houses frequently leads to uncontrolled urban development (i.e. urban sprawl) or even worse: shanty towns. There is also the additional problem of long time periods which span the interval between the strike of a disaster and the provision of a permanent house; the thing which slows the "post-disaster recovery” process in general. Moreover, post-disaster permanent houses are not usually designed for long term accommodation and might thus result in a redundant quality of living for their inhabitants. Another problem which affronts the implementation of SDR and 3SR approaches in Egypt is the huge monetary expense needed to finance the several inherent transitional phases. These transitional phases also necessitate advanced logistics to transport the various sheltering and housing components involved (i.e. tents, transitional shelters and temporary houses) to their designated locations.

On another front, the 2SR approach is not challenged by problems of long time spans or by the drawbacks of transitional phases. However, this approach calls for huge monetary expenses and technological advances for designing structures that are anticipated to last long and for speeding up the permanent construction processes. Apparently, these two important factors are considered shortcomings in the case of Egypt.

\section{Strategies for Enhancing the Approaches}

Despite their apparent shortcomings, the SDR and 3SR approaches have frequently proven themselves indispensable in disaster situations. Accordingly, this research endeavors to synthesize strategies which would "Egyptianize" these approaches through enhancing the prospect of their successful implementation in the country. From comparing these approaches, it can be deduced that their inherent transitional phases accrue long time spans and expenses. Hence, strategies which can expedite these approaches are a logical counter-move against delays and amassed costs.

Expediting the SDR and 3SR approaches opens the door for investigating how to reduce delays in post-disaster housing approaches. Accordingly, synthesizing a strategy which can close the gap between the "emergency response phase" and the permanent housing stage is essential to enhance the 2SR approach. However, in order to succeed, this strategy should be aware of the extended lifetime of the emergency shelters as well as the efforts and expenses required to promote permanent housing construction.

\subsection{Expediting the SDR and 3SR Approaches}

One way of expediting the SDR approach is using modular box units for sheltering and housing. These units should be ready and kept in storage in preparedness to a disaster situation so that once the disaster strikes; the affected community can be easily accommodated. Modular box unit systems are three dimensional spatial elements formed commonly by the combination of wall and floor panels [7]. These systems, constituting an advancement of heavy and light-weight panel systems, can achieve a high degree of completion through factory manufacturing (i.e. the 
prefabrication of temporary shelters and houses). However, occupants are demanded to further develop the units in various ways until they turn into their permanent houses. Novel ideas and innovative designs of box units can be beneficial to the attempt to expedite the SDR approach. For example, the "GA (Ganti + Associates)" Design firm has won an international ideas competition with a radical shipping container skyscraper that was envisioned to provide temporary housing in Mumbai's overpopulated Dharavi Slum [8].

On a relatively different note, the attempt to expedite the 3SR approach should be aware of the fact that this approach involves consecutive processes of relocation. These relocations are sometimes perceived as an inherent aspect of "post-disaster recovery" stages for one or more of the following reasons: (1) People have already been displaced by the disaster; (2) Their current location is judged to be uninhabitable; or (3) Relocation is considered the best option to reduce vulnerability to the risk of future disasters. Relocation of disaster-affected communities requires well-planned and adequately financed programs that include land-for-land exchange, employment generation, ensured food security, and improved access to health services, transportation to jobs, restoration of common properties as well as support for community and economic development.

Expediting the relocation processes (which are inherent to the 3SR approach) can be achieved through "settling-in" abandoned spaces. The idea is to divide up these spaces while transforming them into settlements which can host disaster-affected communities. For example, Levitt Bernstein was announced winner of the open international HOME competition for his intriguing proposal to create pop-up housing in unused garages on London's existing housing estates [9]. In another example, Berlin officials decided in 2015 to convert the abandoned hangers in the Tempelhof airport, Germany into a settlement for refugees. The hangers were divided up into administrative and housing zones which would satisfy the living needs of the people [10].

\subsection{Reducing Delays in the 2SR Approach}

The attempt to close the gap between the "emergency response phase" and the permanent housing stage (in the 2SR approach) would be severely faced in Egypt by the common lack of integration between disaster management plans and traditional urban development schemes (i.e. plans to establish neighborhoods, districts and towns which are typically top-down implemented by the government). Accordingly this research strives to synthesize a strategy which would make post-disaster housing an integral part of governmental development plans.

The strategy (illustrated in Fig. 2) suggests refinements to a typical development scheme which would be prepared by governmental authorities in Egypt to establish a neighborhood. For the sake of argument, the establishment of the neighborhood is proposed to start at the year 2025 and to be completed by the year 2030. The strategy, synthesized in this research, commences by proposing the erection of a building in the year 2017 at the centre of the neighborhood in the exact location which is already preplanned by the government. During the period between 2017 and 2025 (that is to say: before actually starting to establish the neighborhood), the building can be used as a multi-purpose facility to generate income. By the year 2025, and as the establishment of the neighborhood commences, the building would be turned into an administrative/community center. This center would host activities which are essential for inaugurating the establishment of the neighborhood (for example administrative tasks and meetings with community members). By the time the neighborhood is completely established in the year 2030, the building would assume the original function for which it was predestined by the government: act as the neighborhood center.

In order to integrate disaster management plans within this development scheme, the strategy presents 


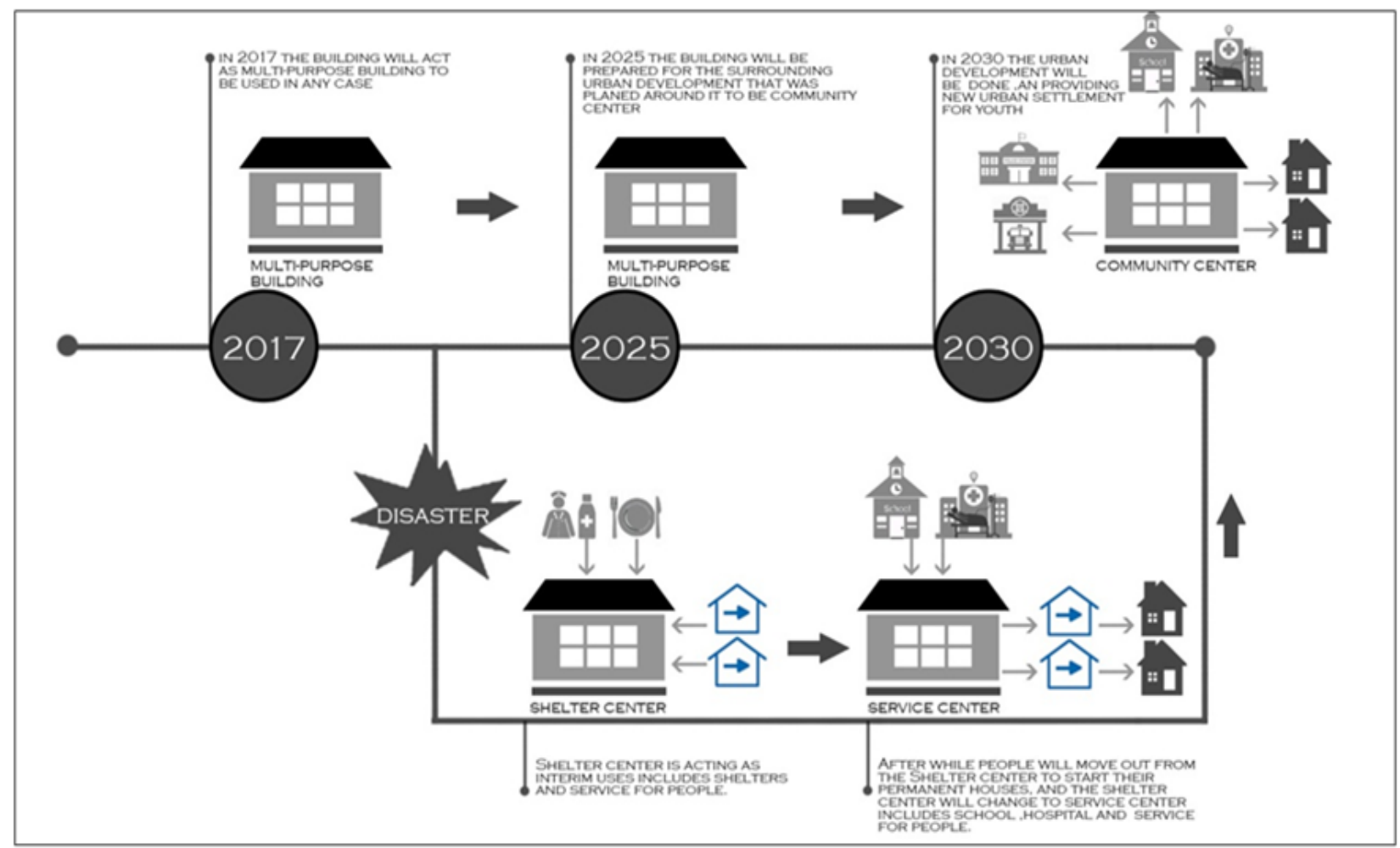

Fig. 2 Strategy for integrating post-disaster housing activities within governmental urban development schemes.

an alternative scenario which involves the strike of a disaster. If a disaster incidence would strike, for instance, in the year 2020, the building (which by this time would be in use as a multi-purpose building in accordance to its original development route) would be turned into an emergency shelter to host disaster-affected communities. With the passage of time, the building would be transformed into a service centre to help sustain "post-disaster recovery" activities (for example: people going back to their old jobs or starting new careers). As the year 2025 approaches, the disaster service centre would be rechanneled into becoming a community centre in order for the disaster recovery scenario to integrally coincide with the original development route. From this point forwards, the building would be developed into a community centre for the affected-communities which would now become the new occupants of the neighborhood.

\section{Conclusions: Recommendations for Implementing Post-disaster Housing Approaches in Egypt}

The use of imported or factory-manufactured (prefabricated) box units in Egypt would face considerable difficulties including cost insufficiency and the absence of the technological capabilities needed for utilization. Should this strategy be used to expedite the SDR in a developing country such as Egypt, the units' cost should be kept relatively lower than that of a permanent house which might be constructed in less time and cheaper than an imported or prefabricated unit. One way of doing this is using low-tech techniques and local materials which allow the units to be manufactured in-situ. These refinements to the original strategy might also compensate for the lack of skilled labor, heavy-duty equipment, precision measurement and handling for in-position placement. In-situ construction of units allows a response team 
(composed of expertise and locals) to rapidly deliver and set up emergency housing faster than most other approaches which depend on technically-demanding installations typical to factory-manufacturing. Moreover, in-situ construction would decrease the need for transporting the units to their designated locations (for examples on vehicular trailers or train carts). On a related note, post-disaster housing units need to be designed in a way which can result in a variety of configurations while providing their occupants with enough flexibility to apply changes to their homes. The units should be also allowed to connect together to provide larger living quarters.

The processes of relocation, inherent to the 3SR approach, are associated with cancerous growth of slums particularly in the fast growing cities of Asia and Africa; the thing which poses a challenge for providing adequate basic services and infrastructure. This challenge is central to the economic performance of cities, and their ability to provide a minimum quality of life to their citizens. To this end, the attempt to expedite the 3SR approach by transforming abandoned spaces into settlements should be aware of the resultant density and quality of living.

Establishing settlements outside of cities' boundaries is a counter-measure against inner-city urban sprawl because these newly occupied spaces can be nuclei for future development.

The attempt to close the gap between "emergency response phase" and the permanent housing stage in the 2SR approach should ideally be implemented with the following recommendations in mind:

- Encouraging the participation of affected communities in critical decisions concerning relocation and implementation;

- Establishing channels of communication with target groups to resolve difficulties and challenges;

- Grouping people from similar same communities together in a new settlement;

- Designing houses, settlement layouts and community facilities to suit the community of life;
- Assessing disaster-induced risks to make sure that these risks cannot be mitigated in the old location, while the community can be assured the absence of these risks in the new settlement.

\section{References}

[1] McCarthy, F. X. 2010. FEMA Disaster Housing: From Sheltering to Permanent Housing. Congressional Research Service Publications.

[2] Emergency Operations and Emergency Response Team (Shelter and Settlements). 2011. How-to Guide: Managing Post-Disaster (Re)-Construction Projects. Catholic Relief Services. Accessed June 6, 2018. https://www.crs.org/sites /default/files/tools-research/managing-postdisaster-recons truction-projects.pdf.

[3] Félix, D., Monteiro, D., Branco, J. M., Bologna, R., and Feio, A. 2015. "The Role of Temporary Accommodation Buildings for Post-disaster Housing Reconstruction.” Journal of Housing and the Built Environment 30 (May): 683-99.

[4] Shelter Centre. 2012. Transitional Shelter Guidelines. Geneva: Shelter Centre, IOM, DFID \& Sida. Accessed May 7, 2017. https://www.iom.int/files/live/sites/iom/ files/What-We-Do/docs/Transitional-Shelter-Guidelines.p df.

[5] International Federation of Red Cross and Red Crescent Societies. 2013. Post-disaster Shelters: Ten Designs. Geneva IFRC Publications. Accessed January 07, 2017. http://shelterprojects.org/files/tshelter-8designs/10designs 2013/2013-10-28-Post-disaster-shelter-ten-designs-IFRClores.pdf.

[6] Reckford, J. 2012. Shelter Report 2012 Build Hope: Housing Cities after a Disaster. Atlanta: Habitat for Humanity. Accessed March 12, 2017. https://www.habitat.org/sites/default/files/gov_shelter_re port_2012_entire.pdf.

[7] Eren, O. 2008. "Box Construction Systems Application Principles.” A paper presented on CIB Joint International Symposium, Dubai, Herriot-Watt University.

[8] Rosenfield, K. 2015. "GA Designs Radical Shipping Container Skyscraper for Mumbai Slum; 24-08-2015.” Archdaily Official Website. Accessed April 9, 2017. https://www.archdaily.com/772414/ga-designs-radical-sh ipping-container-skyscraper- for-mumbai-slum.

[9] The Guardian. 2012. "Garages to Provide 'Pop-up' Housing for Homeless People; 12-09-2012.” Official Website of the Guardian (international edition). Accessed April 9, 2017. https://www.theguardian.com/artand design/architecture-design-blog/2012/nov/12/garages-hou sing-homeless-people. 
[10] Bell, J. 2015. "Refugee Crisis: The Nazi-era Airport That's Now 'Home' to 3,000 Refugees; 31-12-2015.” The Official Website of the Independent. Accessed April 11,
2018. https://www.independent.co.uk/news/world/europe /refugee-crisis-the-tempelhof-nazi-airport-hangar-thats-n ow-a-home-for-3000-refugees-a6791741.html. 